\title{
Getting information on suspended sediments in a large river from acoustic backscatter
}

\author{
Adrien Vergne ${ }^{1, *}$, Céline Berni ${ }^{1}$, and Jérôme Le $\mathrm{Coz}^{1}$ \\ ${ }^{1}$ Irstea, UR RiverLy, centre de Lyon-Villeurbanne, 5 rue de la Doua CS 20244, 69625 Villeurbanne, \\ France
}

\begin{abstract}
There has been a growing interest in the last decade in extracting information on Suspended Sediment Concentration (SSC) from acoustic backscatter in rivers. Quantitative techniques are not yet effective, but acoustic backscatter already provides qualitative information on suspended sediments. In particular, in the common case of a bi-modal sediment size distribution, corrected acoustic backscatter can be used to look for sand particles in suspension and provide spatial information on their distribution throughout a river crosssection. This paper presents a case-study where these techniques have been applied.
\end{abstract}

\section{Introduction}

The acoustic backscatter signal recorded in a river with a profiler such as an Acoustic Doppler Current Profiler (ADCP) or an Acoustic Backscatter System (ABS) is known to be closely related to the presence and the characteristics of the particles in suspension. So far, existing acoustic scattering models and their input variables are too imprecise for ending up with quantitative measurement of the suspended sediment concentration (SSC) without in situ calibration. However, multi-frequency acoustic measurements can provide interesting qualitative spatial information on the suspension. This paper presents a case study of backscatter signal analysis throughout a river cross-section in high suspended sediment load conditions.

\section{Study site and measurements}

The data presented here were recorded during a field campaign conducted at Isère River confluence (France, Fig. 1a) on January $6^{\text {th }} 2018$, while an upstream dam flushing carried out during a flood event. An ABS Aquascat 1000R was deployed from a boat (Fig. 1b) to record the backscatter signal throughout the river cross-section, using 4 down-looking transducers at $0.3,0.5,1.0$ and $5.0 \mathrm{MHz}$. This instrument records a normalised tension $V$ which is proportional to the root mean square of the acoustic pressure. Sonar pinging frequency was set to $16 \mathrm{~Hz}$, and the position of the vessel was recorded every 2 seconds using a GPS. A surface water sample was taken at the center of the cross-section for SSC analysis.

\footnotetext{
*e-mail: adrien.vergne@irstea.fr
} 
(a)

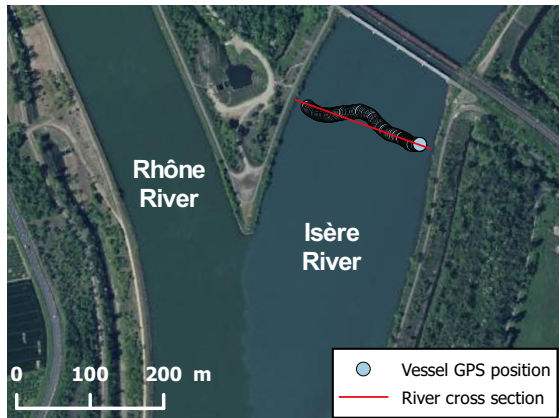

(b)

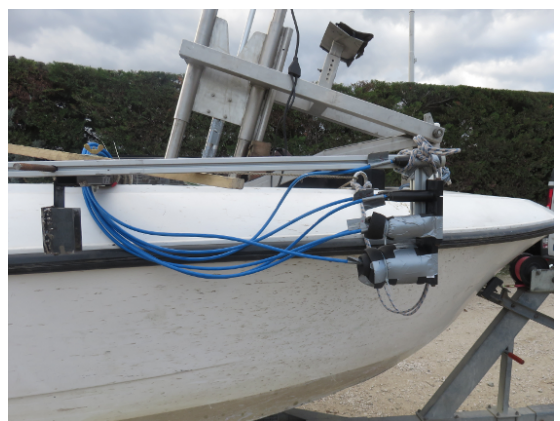

Figure 1: (a) Study site and river cross-section ; (b) Aquascat 1000R transducers mounted on a boat. The transducers were moved down into the water for the measurements.

\section{Bimodal suspension hypothesis}

Very often, a bimodal suspended sediment size distribution is observed in large rivers (e.g. [1]), the first mode being usually composed of fine silt and clay particles, and the second one of fine to coarse sand. The fine mode is generally relatively well mixed over the river cross section, while the sand mode is mostly found close to the bed and presents strong vertical and lateral gradients. In terms of acoustics, fine sediments induce high attenuation but low backscatter signal, while sand particles produce a much stronger echo and less attenuation. This effect has been already used to discriminate the response of the fine and sand modes in large rivers with horizontal ADCPs [2]. It allows to perform in situ calibration of both fine and sand SSC in relation to acoustics [3], in the case where the suspension is homogeneous along the acoustic beam.

Long term monitoring of Isère River sediment load carried out as part of the Rhône Sediment Observatory (OSR) program showed that sand can be transported in suspension at this site, particularly during dam flushing operations as that was the case in this study. Fine and sand mode particle size are typically $\sim 10 \mu \mathrm{m}$ and $\sim 100 \mu \mathrm{m}$ respectively. Thus, we try here to check whether the fine suspension was actually homogeneous, and we process the acoustic signal to look for sand backscattering evidence.

\section{Acoustic backscatter signal analysis}

\subsection{Signal to Noise Ratio}

The raw backscatter profiles have been first projected on the river cross-section using GPS data. They have been averaged in quadratic mean every 1 meter $(\sim 25$ profiles $/ \mathrm{m})$ in order to reduce the signal variability due to both the random phase of the acoustic scattering processes and the unsteadiness of the suspended sediment load. River acoustic backscatter measurements are very sensitive to noise issues because of the potential presence of small particles $(<10 \mu \mathrm{m})$ that produce a weak echo but could lead to strong signal attenuation. Background noise levels $V_{\text {noise }}$ have been estimated at each frequency by fitting the tails of the time-averaged backscatter profiles as presented in Figure 2.

The Signal to Noise Ratio $\left(\mathrm{SNR}=V^{2} / V_{\text {noise }}^{2}\right)$ is then computed throughout the river cross section (Fig. 3). We consider SNR $=2$ as the lowest instrument detection level. One can see in Figure 3 that the effective particle detection range is about 4, 3, 2.5, and $0.6 \mathrm{~m}$ at $0.3,0.5,1.0$ and 5.0 MHz respectively. This illustrates the importance of SNR analysis to identify blind zones: an incorrect interpretation would have been to take the signal into account down to the 

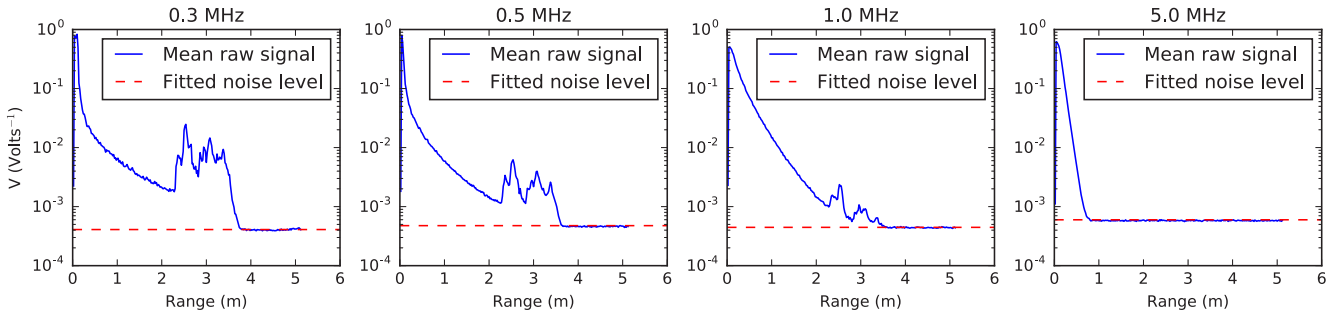

Figure 2: Estimation of the background noise levels using the tails of the time-averaged raw profiles

bottom of the river as far as the bed echo is visible. For example, the $5 \mathrm{~m}$-deep river bottom is acoustically visible at $0.5 \mathrm{MHz}$, while suspended particles are invisible after approximately $3 \mathrm{~m}$ (see Fig. 3). This is due to the bed reflection being much stronger than the particle backscattering.

We consider the background noise non-negligible for $\mathrm{SNR}<10$, which corresponds to a large part of the river cross-section as shown in Figure 3. The raw signal is therefore corrected from noise to obtain $V_{c o r}$ :

$$
V_{\text {cor }}=\sqrt{V^{2}-V_{\text {noise }}^{2}}
$$
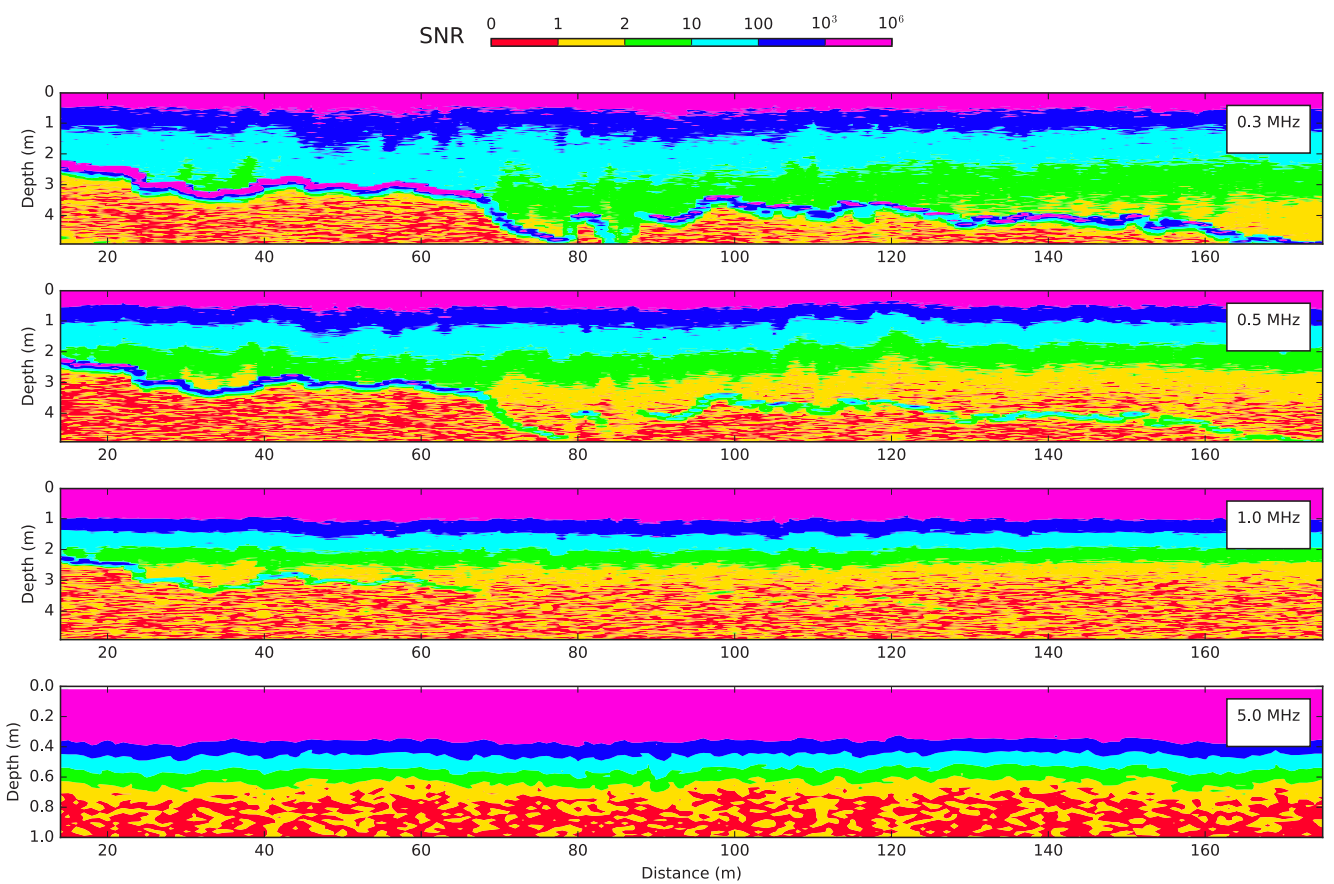

Figure 3: SNR throughout the river cross-section. Horizontal distance is measured from left to right bank. Note that the depth scale is different at 5.0 MHz. 
Figure 3 also provides information on the suspension. Short detection ranges are the result of strong signal attenuation, that indicates a high concentration $(>1 \mathrm{~g} / \mathrm{l})$ of fine suspended sediments. The backscatter level is therefore mainly driven by attenuation, and in Figure 3 SNR horizontal stripes can be interpreted as a clue of relatively homogeneous attenuation laterally, i.e. fairly homogeneous concentration of fine sediments laterally.

\subsection{Fluid Corrected Backscatter}

The acoustic signal is now corrected from water attenuation and spherical spreading to obtain the Fluid Corrected Backscatter (FCB):

$$
\mathrm{FCB}=\ln \left(\mathrm{V}_{\text {cor }}\right)+\ln (\mathrm{r})+2 \alpha_{\mathrm{w}} \mathrm{r}
$$

where $r$ is the range from the instrument, computed from instrument cell size and sound velocity, and $\alpha_{w}$ is the water attenuation coefficient evaluated from the temperature (see Tab. 1). The sonar equation [4] leads to:

$$
\mathrm{FCB}=\ln \left(\Re \sqrt{s_{v}}\right)-2 \alpha_{\mathrm{s}} \mathrm{r}
$$

where $\Re$ is a constant depending on the instrument that can be measured through calibration [5], $s_{v}$ is the volume backscattering coefficient [6] and $\alpha_{s}$ the attenuation due to suspended sediments. For a homogeneous suspension, $s_{v}$ is constant with range and $\mathrm{dFCB} / \mathrm{dr}=-2 \alpha_{\mathrm{s}}$. Figure 4 shows that cross-section averaged FCB are fairly linear with range in the first $2 \mathrm{~m}$ of the water column. This is a clue of fine sediment suspension being vertically homogeneous, at least in the upper part of the river cross-section. The sediment attenuation coefficients $\alpha_{s}$ computed from FCB are compared to water attenuation in Table 1. Note that $\alpha_{s}>>\alpha_{w}$, which confirms a high concentration of fine sediments and reduces the need for precise temperature measurement in $\alpha_{w}$ estimation.
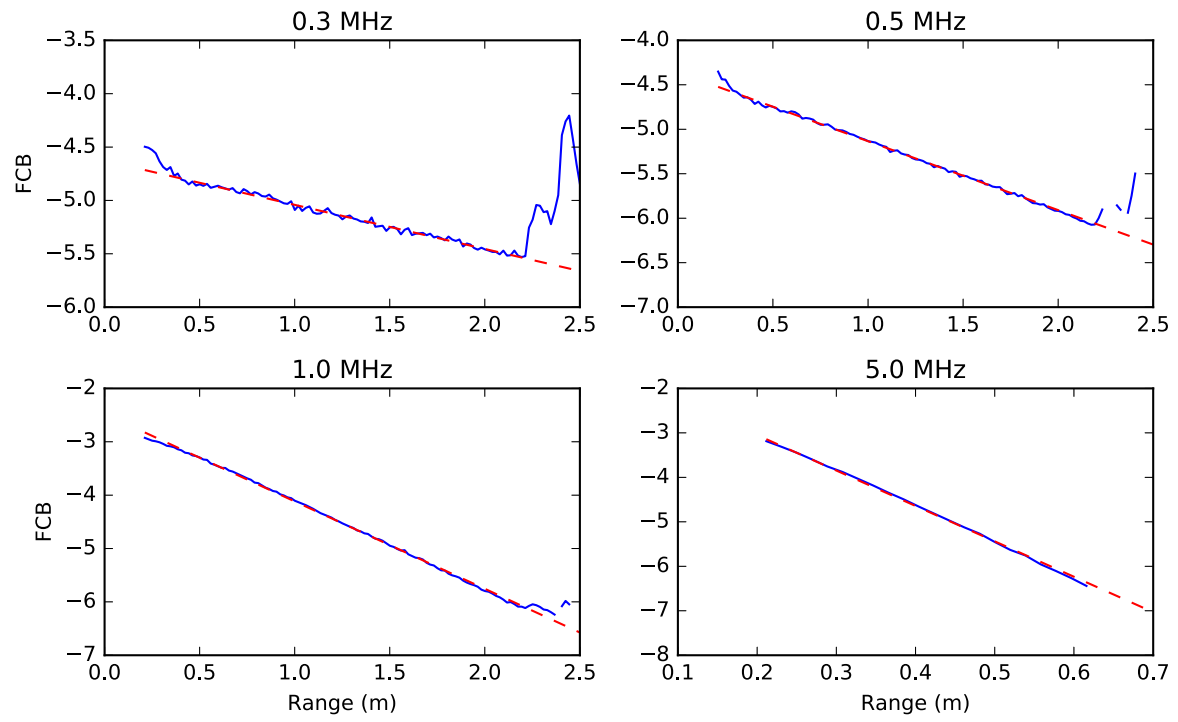

Figure 4: Mean Fluid Corrected Backscatter profiles averaged over the river cross-section. Dashed red lines show the linear fits. 


\begin{tabular}{lllll}
\hline & $\mathbf{0 . 3} \mathbf{~ M H z}$ & $\mathbf{0 . 5} \mathbf{M H z}$ & $\mathbf{1 . 0} \mathbf{M H z}$ & $\mathbf{5 . 0} \mathbf{M H z}$ \\
\hline$\alpha_{s}\left(\mathrm{~m}^{-1}\right)$ & 0.207 & 0.388 & 0.820 & 3.957 \\
$\alpha_{w}\left(\mathrm{~m}^{-1}\right)$ & 0.003 & 0.010 & 0.039 & 0.970 \\
\hline
\end{tabular}

Table 1: Sediment attenuation coefficient $\alpha_{s}$ estimated from FCB slope and water attenuation coefficient $\alpha_{w}$ computed from water temperature $\left(=8^{\circ} \mathrm{C}\right)$

\subsection{Fine sediments correction}

Given SNR and FCB clues of fine mode being relatively homogeneous throughout the river cross-section, we make the hypothesis of a bi-modal suspension as presented in section 3 . The attenuation computed from FCB is considered homogeneous throughout the river crosssection, and is added to FCB to get the Fluid and Sediment Corrected Backscatter (FSCB):

$$
\begin{aligned}
\mathrm{FSCB} & =\ln \left(V_{c o r}\right)+\ln (r)+2\left(\alpha_{w}+\alpha_{s}\right) r \\
& =\mathrm{FCB}+2 \alpha_{\mathrm{s}} \mathrm{r} \\
& =\ln \left(\Re \sqrt{s_{v}}\right)
\end{aligned}
$$

Assuming the sand mode to be mainly located near the bottom of the river, we compute the mean ambient backscatter $V_{a m b}$ by averaging $\mathrm{e}^{\mathrm{FSCB}}$ over the river cross-section in the first $1 \mathrm{~m}$ of the water column (removing near-field effects when needed). The $V_{a m b}$ backscatter signal might not only be due to fine sediment particles, but also to flocculated particles and air micro-bubbles. As for the attenuation, we consider this signal to be constant throughout the river cross-section. By removing $V_{a m b}$ from the previously corrected backscatter, we expect to obtain the backscatter signal $V_{\text {sand }}$ produced by sand particles:

$$
V_{\text {sand }}^{2}=\mathrm{e}^{2 \mathrm{FSCB}}-V_{a m b}^{2}
$$

Given all the assumptions we made and considering sand attenuation to be negligible compared to fine particles attenuation, we have:

$$
V_{\text {sand }}^{2}=\Re^{2} s_{v, \text { sand }} \propto d_{\text {sand }}^{n} M_{\text {sand }}
$$

where $s_{v \text {,sand }}$ is the volume backscattering coefficient of sand, $d_{\text {sand }}$ the diameter of the sand particles and $M_{\text {sand }}$ their mass concentration. The exponent $n$ is likely to be close to 3 in the Rayleigh regime [6], that is when $k d_{\text {sand }} / 2<<1$ where $k$ is the wave number (particles $<500 \mu \mathrm{m}$ in diameter are in this case at 0.3 and $0.5 \mathrm{Mhz}$ ). Thus, an increase of $V_{\text {sand }}^{2}$ level might indicate an increase in particle size and / or concentration. Figure 5 shows $V_{\text {sand }}^{2}$ signal over the river cross-section at 0.3 and $0.5 \mathrm{MHz}$.

\section{Results and discussion}

Water sample analysis showed that the sediment concentration was $\sim 9.1 \mathrm{~g} / \mathrm{L}$ at the surface, with only $2 \%$ (in mass) of particles $>63 \mu \mathrm{m}$. It confirms a high concentration of fine sediments and low concentration of sand in the upper part of the water column. It is also coherent with previous measurements of fine sediments attenuation carried out nearby in the same river with horizontal ADCPs during a similar dam flushing event on June 30th 2010 [7]. As an example, the relation between SSC and sound attenuation at $0.3 \mathrm{MHz}$ found in [7] would predict a SSC of $12.2 \mathrm{~g} / \mathrm{L}$ in the present case study, which is in the right order of magnitude. 

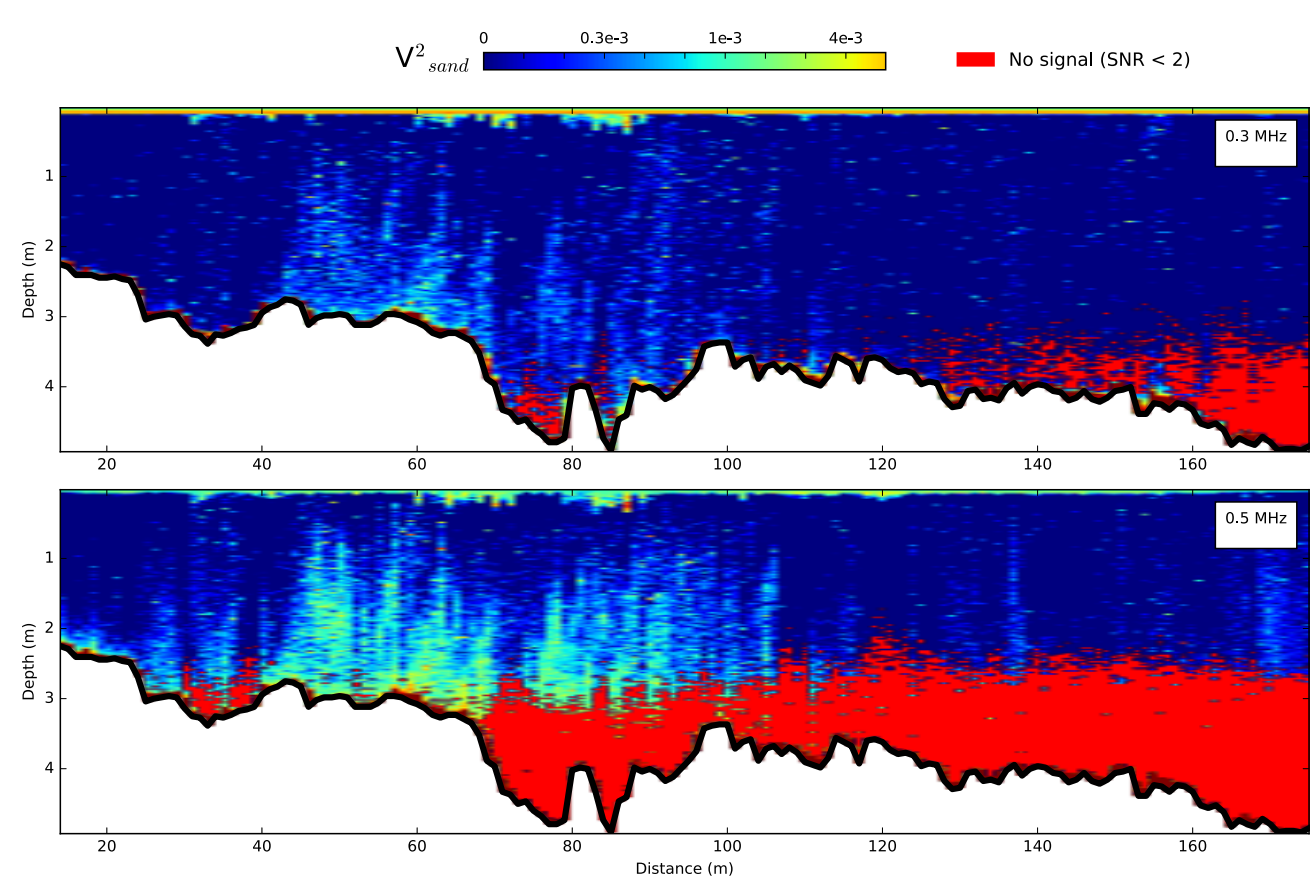

Figure 5: Sand backscatter signal $V_{\text {sand }}^{2}$ throughout the river cross-section at 0.3 and $0.5 \mathrm{MHz}$. Red zones show where the signal should not be interpreted because $\mathrm{SNR}<2$.

One can see in Figure 5 that $V_{\text {sand }}^{2}$ backscatter level is quite non-homogeneous throughout the river cross-section, and is globally increasing with depth as expected for the sand mode. Stronger particle echo at $0.5 \mathrm{MHz}$ suggests that the backscatter is located in the Rayleigh domain, i.e. the particles are relatively small $(<500 \mu \mathrm{m})$. Figure 5 suggests that suspended sand particles were mainly transported in the range 40-100 m from left bank. Given the bend of the river at this site (Fig. 1a), the main water flow was located on the right side of the cross-section. Thus, Figure 5 suggests that sand particles might have been re-suspended from a local bar, and were not coming from far upstream.

Figure 5 also shows the intrinsic limitation of hydro-acoustic technologies in monitoring river SSC: as frequency increases, more precise information is obtained on the suspended particles because of better sensitivity; but the detection range decreases drastically.

The use of multi-frequency ABS opens prospects of moving from qualitative to quantitative results in monitoring river SSC and particle size with acoustics. The current limitations of such techniques include the need for an accurate instrument calibration that is not easy to perform at low frequency $(<1.0 \mathrm{MHz})$ due to large transducer size ; the lack of accurate scattering models suitable for river suspended particles ; and a poor understanding of non-solid particle scatterers such as flocs and air micro-bubbles.

\section{References}

[1] Y.C. Agrawal, D.M. Hanes, Water Resources Research 51, 8854 (2015)

[2] D.J. Topping, S.A. Wright, T.S. Melis, D.M. Rubin, High-resolution measurements of suspended-sediment concentration and grain size in the Colorado River in Grand Canyon 
using a multi-frequency acoustic system, in Proceedings of the 10th International Symposium on River Sedimentation (Russia, Moscow, 2007), Vol. III, pp. 330-339

[3] D.J. Topping, S.A. Wright, Long-term continuous acoustical suspended-sediment measurements in rivers-Theory, application, bias, and error, U.S. Geological Survey Professional Paper 1823 (2016), http: //dx . doi . org/10.3133/pp1823

[4] P.D. Thorne, D. Hurther, Continental Shelf Research 73, 97 (2014)

[5] K.F.E. Betteridge, P.D. Thorne, R.D. Cook, Continental Shelf Research 28, 227 (2008)

[6] H. Medwin, C.S. Clay, Fundamentals of Acoustical Oceanography (Academic Press, 1998)

[7] S.A. Moore, J. Le Coz, D. Hurther, A. Paquier, Continental Shelf Research 46, 50 (2012) 